\section{RMD Open}

Rheumatic \&

Musculoskeletal Diseases
To cite: Sigurdardottir V, Jacobsson L, Schiöler L, et al. Occupational exposure to inorganic dust and risk of gout: a population-based study. RMD Open 2020;6:e001178. doi:10.1136/rmdopen-2020001178

- Additional material is published online only. To view please visit the journal online (http://dx.doi.org/10.1136/rmdo pen-2020-001178).

$\mathrm{MD}$ and $\mathrm{KT}$ share senior authorship.

Received 13 January 2020 Revised 4 May 2020 Accepted 7 June 2020

Check for updates

(C) Author(s) (or their employer(s)) 2020. Re-use permitted under CC BY-NC. No commercial re-use. See rights and permissions. Published by BMJ.

${ }^{1}$ Department of Rheumatology and Inflammation Research, Institute of Medicine, The Sahlgrenska Academy at University of Gothenburg, Gothenburg, Sweden ${ }^{2}$ Center for Clinical Research Dalarna, Uppsala University, Falun, Sweden

${ }^{3}$ Occupational and

Environmental Medicine, School of Public Health and Community Medicine, Sahlgrenska Academy, University of Gothenburg, Goteborg, Sweden

Correspondence to Valgerdur Sigurdardottir; valger dur.sigurdardottir@regionda larna.se

\title{
Occupational exposure to inorganic dust and risk of gout: a population-based study
}

\author{
Valgerdur Sigurdardottir (iD, ${ }^{1,2}$ Lennart Jacobsson, ${ }^{1}$ Linus Schiöler, ${ }^{3}$ Anna Svärd, ${ }^{2}$ \\ Mats Dehlin, ${ }^{1}$ Kjell Toren ${ }^{3}$
}

\section{ABSTRACT \\ Background Risk factors operating independently of hyperuricemia could be of importance in determining why only a minority of people with hyperuricemia develop gout. Exposure to inorganic dust has been linked to other inflammatory diseases and could influence the development of gout. Objectives To evaluate if occupational exposure to inorganic dust increases the risk of gout.}

Methods Individuals aged 30-65 years with a first gout diagnosis in 2006-2012 in the population-based healthcare database of the Western Swedish Healthcare Region (VEGA) and population controls matched by age and sex were included. Data on occupation was collected from the Swedish occupational register. Exposure status was assigned by means of a job exposure matrix. Data on gout-related comorbidities was collected from VEGA. Alcohol use disorder and obesity were related both to gout and exposure to inorganic dust and were adjusted for in multivariate analyses. ORs were calculated using conditional logistic regression. Results 5042 gout cases and 20682 controls were included. Exposure to inorganic dust was associated with gout in both unadjusted (OR 1.12,95\% $\mathrm{Cl} 1.04$ to 1.20 ) and multivariate (OR $1.08,95 \% \mathrm{Cl} 1.00$ to 1.16 ) analyses of the whole population. In sex-stratified multivariate analyses, dust exposure was significantly associated with gout in women (adjusted OR 1.26, 95\% Cl 1.05 to 1.51), but not in men (adjusted OR 1.05, 95\% Cl 0.97 to 1.13).

Conclusions We describe for the first time an association between exposure to inorganic dust and gout. After adjusting for confounders, the findings were statistically significant for women but not for men.

\section{INTRODUCTION}

It is well established that hyperuricemia is a prerequisite of gout and that the risk of clinical gout increases in the presence of factors that increase serum urate levels, such as renal disease, ${ }^{12}$ alcohol use disorder, ${ }^{3}{ }^{4}$ diuretic use ${ }^{5}$ and obesity. ${ }^{6}$ Some of these urate-elevating factors, such as alcohol use disorder and obesity, are associated with lower socioeconomic status (SES) as measured by income and level of education. ${ }^{7}$ This could in part explain the observation that gout is more common among people of lower SES. A number of epidemiological studies have found an increased prevalence of gout

\section{Key message}

What is already known about this subject?

- Exposure to inorganic dust has been shown in several studies to associate with a number of rheumatic inflammatory diseases such as rheumatoid arthritis and systemic sclerosis, but it has not been investigated previously whether exposure is associated with an increased risk of gout.

- Inorganic dust, like silica, can activate the NLRP3 inflammasome, a key component in the inflammatory response to urate crystals, subsequently leading to clinical gout.

What does this study add?

- We demonstrate for the first time an association between occupational exposure to inorganic dust and incident gout.

- The findings are indicative of a previously unknown possible aetiological avenue for gout, in addition to known risk factors like genetics, diet and urateelevating comorbidities.

How might this impact on clinical practice?

- If confirmed, the findings could provide a possibility for prevention of gout among susceptible individuals by minimising exposure to inorganic dust in the work environment.

among people with shorter education, lower income and manual occupations, ${ }^{811}$ where the difference is not fully explained by different rates of urate-elevating comorbidities or serum urate levels. The mechanism behind lower SES predisposing to gout independently of urate levels or urate-elevating comorbidities is unknown. One possible explanation is that yet unknown occupational exposures increasing the risk for gout could be more common in lower socioeconomic groups. Very little is known about the possible influence of occupational exposures on the risk of gout in recent times. It is possible that, yet unknown, exposures present in the work environment of today could increase the susceptibility to gout, by accenting either hyperuricemia, the process of 
monosodium urate (MSU) crystallisation or the inflammatory response to MSU crystals.

Exposure to inorganic dusts, for example, silica dust, is one such occupational exposure that may be related to gout. Silica dust has been shown to activate the NLRP3 inflammasome, ${ }^{12}$ which is a key component of the inflammatory response to MSU crystals. ${ }^{13}$ Exposure to silica has also been associated with renal disease, ${ }^{14}$ which could facilitate the development of hyperuricemia and gout. Exposure to inorganic dust has recently been shown in several studies to associate with a number of other rheumatic inflammatory diseases such as rheumatoid arthritis and systemic sclerosis. ${ }^{15} 18$ Increased levels of ambient air pollution, especially regarding the component of air pollution consisting of fine particular matter $<10 \mu \mathrm{M}$, have been reported to increase the occurrence of acute gout flares, ${ }^{19}$ but no studies investigating the possible association of occupational exposure to inorganic dust with gout are available.

The aim of the present study was therefore to examine if previous occupational exposure to inorganic dust predicted an incident diagnosis of gout, both overall and stratified by sex.

\section{MATERIALS AND METHODS}

Study design

This is a population-based nested case-control study including all individuals with a first diagnosis of gout in the years 2006-2012 and matched population controls without gout. Cases were matched to controls by age, sex and place of residence on municipality level. Up to five controls were matched to each individual with gout. In Sweden, each resident has a unique personal identification number that identifies records in official registers, enabling linking of data from different sources. For this study, we used data from several national and regional registers (described below) to identify individuals with gout and population controls and to define occupational exposure to inorganic dust as well as information on relevant confounders for the analyses.

\section{Setting and study population}

The Swedish healthcare system is tax-funded and offers universal access. Gout is typically diagnosed and treated in a primary care setting. All inhabitants in the Western Swedish Healthcare Region (WSHCR) from January 1, 2006 to December 31, 2012 constituted the study population. The population of WSHCR is approximately 1.6 million (20\% of the total population of Sweden), ${ }^{20}$ and the region is considered to be representative for Sweden with regard to health status, healthcare-seeking and socioeconomics. ${ }^{20} 21$

\section{Register sources}

Western Swedish Healthcare Register (VEGA)

The register contains information about all healthcare contacts in primary care and inpatient and outpatient secondary care clinics in the WSHCR. Date of contact and primary and secondary diagnoses given by the treating physician according to the Swedish version of the International Statistical Classification of Diseases (ICD) are registered. VEGA was used to identify gout cases and to retrieve information about relevant comorbidities for cases and controls. For gout cases, the date of the first gout diagnosis was used as the index date/date of identification.

\section{Swedish Census Register}

The census register holds demographic information about all registered inhabitants of Sweden including dates of death and emigration. The census register was used to identify up to five controls for each case, matched for age, sex and place of residence on municipality level at the date of identification. Controls were assigned the same index date/date of identification as their corresponding case.

Longitudinal Integration Database for Health Insurance and Labour Market Studies

The register is administered by Statistics Sweden. The database holds annual registers since 2001 on all individuals from 16 to 64 years of age, including information about occupation, employment status and educational level. Occupation is registered according to The Swedish Standard Classification of Occupations (SSYK) classification, which is based on the International Standard Classification of Occupations- $88 .^{22}$ Data on occupation is provided by employers. Complete data on occupation was available for between $91 \%$ and $94 \%$ of the population during the years 2001-2008. ${ }^{35}$

\section{Swedish Prescribed Drug Register}

All prescribed drugs dispensed by Swedish pharmacies are recorded in the Swedish Prescribed Drug Register. The register has been available since July 1, 2005 and was used to determine dispensation of urate lowering therapy (ULT) and diuretics.

\section{Case definition and selection of controls}

To select individuals most likely to have new-onset gout, we included individuals with a diagnosis of gout in the VEGA register during 2006-2012. The VEGA database was then searched for gout diagnoses back to January 1, 2000, and individuals with a prior diagnosis of gout were excluded. All included individuals thus have a period free from gout diagnosis of at least 5 years before their index date. Gout diagnosis was defined by the presence of an ICD-10 code for gout (M10), registered at a visit to a physician in the VEGA database. We excluded cases and controls with dispensation of ULT- prior to first gout diagnosis or corresponding date for controls. The case definition has been previously validated by means of record review that showed a high validity of ICD-10 codes for gout in the VEGA database. ${ }^{23}$

To ensure that the population included was part of the workforce, we included only individuals that were of 
working age (30-65 years) at the time of gout diagnosis and that had at least one registered occupation during the 5 years prior to the year of identification with gout.

We applied the same conditions to the population controls, excluding controls with no occupation registered for the 5 years prior to the year of identification as control. The selection of cases and controls for the study is further described in online supplementary table 1 .

\section{Exposure}

The occupational register was searched for registered occupational codes during the 5 calendar years prior to identification as case or control, that is, occupations on file in the occupational register for the years 2002-2006 contributed to exposure assignment for an individual that was identified as case or control in 2007. A job exposure matrix (JEM) for inorganic dust previously developed was used to assess exposure. ${ }^{24}$ During development of the JEM, all occupations were re-assessed by two senior occupational hygienists as being occupationally exposed or not to inorganic dust including silica dust as previously described. ${ }^{24} 25$ An exposed occupation was defined based on the assumption that at least half of the subjects with these specific codes should have a strong probability of being exposed.

Individuals that had been employed in a dust-exposed occupation for at least 1 year during the 5 -year-long predictor period were defined as exposed.

\section{Definition of comorbidities}

Comorbidities known to be associated with gout were identified in VEGA by ICD-10 codes. VEGA was searched from 2000 to 2012 for predefined comorbidities (for definitions used, see online supplementary table 2). A comorbidity was considered present if there was a healthcare contact with a corresponding ICD-10 coded diagnosis by a physician before the index date.

\section{Statistics}

The association between occupational exposure to inorganic dust and incident gout diagnosis was assessed using conditional logistic regression, accounting for the matched design of the study. Results are presented as unadjusted and adjusted ORs with 95\% CIs, for the whole population and stratified by sex.

The covariates adjusted for in the analysis (alcohol use disorder and obesity) were chosen on the basis of being plausible confounders, that is, related to the outcome of gout based on prior clinical knowledge ${ }^{3426}$ through the mechanism of elevating urate levels and associated with exposure to inorganic dust in our data (online supplemen tary tables 3-4). Other gout-related urate-elevating comorbidities, for example, renal disease and psoriasis, were not included in the multivariable analysis as they have no known association with occupational exposure to inorganic dust nor were they associated with dust exposure when this was tested in our own data (online supplementary tables 5-6).

In a secondary model, in addition to the covariates described above, we also adjusted for educational level.

\section{RESULTS}

\section{Baseline characteristics of cases and controls}

A 5042 gout cases and 20682 population controls fulfilling the case definition were identified and included for analysis. Baseline characteristics of included individuals are shown in table 1 .

\section{Exposure to inorganic dust}

Among individuals with incident gout, $30.1 \%$ were occupationally exposed to inorganic dust during the 5 -year period preceding the index date, whereas $28.2 \%$ of population controls were exposed $(\mathrm{p}=0.006)$.

Among men, $34.4 \%$ of gout cases and $33.0 \%$ of the population controls were exposed to inorganic dust, corresponding to $1.4 \%$ (95\% CI $0.2 \%$ to $3.1 \%$ ) higher exposure frequency among the gout cases. In women, $16.0 \%$ of gout cases and $12.7 \%$ of controls were exposed, corresponding to $3.3 \%$ (95\% CI $1.2 \%$ to $5.5 \%$ ) higher exposure frequency among the gout cases (figure 1).

\section{Association of exposure to inorganic dust to incident gout} Exposure to inorganic dust was associated with incident gout in the unadjusted analysis of the whole population (OR 1.12, 95\% CI 1.04 to 1.20 ). In the multivariate analysis, after adjustment for alcohol use disorder and obesity, exposure to inorganic dust increased the odds of incident gout by $8 \%$ (OR 1.08, 95\% CI 1.00 to 1.15 ) (figure 2A). In the results of the secondary model, where educational

\begin{tabular}{|c|c|c|}
\hline Variable & $\begin{array}{l}\text { Gout } \\
\text { cases, } \\
n=5042\end{array}$ & $\begin{array}{l}\text { Population } \\
\text { controls, } \\
n=20682\end{array}$ \\
\hline Men & $3862(76.6)$ & $15747(76.1)$ \\
\hline Age, mean(SD) & $52.9(8.9)$ & $52.7(8.9)$ \\
\hline Education level $>12$ years & $1283(25.4)$ & $6912(33.4)$ \\
\hline $\begin{array}{l}\text { Exposed to inorganic dust } \\
\text { during predictor period }\end{array}$ & 1519 (30.1) & $5822(28.2)$ \\
\hline \multicolumn{3}{|l|}{ Comorbidities } \\
\hline Hypertension & 2096 (41.6) & $4474(21.6)$ \\
\hline Treatment with diuretics & 1350 (26.8) & $1969(9.5)$ \\
\hline Obesity & $499(9.9)$ & $671(3.2)$ \\
\hline Diabetes & $405(8.0)$ & 878 (4.2) \\
\hline Renal disease & $357(7.1)$ & $659(3.2)$ \\
\hline Coronary heart disease & $263(5.2)$ & $484(2.3)$ \\
\hline Atrial fibrillation & $242(4.8)$ & $314(1.5)$ \\
\hline Alcohol abuse & $253(5.0)$ & $431(2.1)$ \\
\hline Thromboembolism & $210(4.2)$ & $452(2.2)$ \\
\hline Congestive heart failure & $196(3.9)$ & $138(0.7)$ \\
\hline Psoriasis & $174(3.5)$ & $518(2.5)$ \\
\hline Stroke & $93(1.8)$ & $235(1.1)$ \\
\hline $\begin{array}{l}\text { Chronic obstructive } \\
\text { pulmonary disease (COPD) }\end{array}$ & $71(1.4)$ & $116(0.6)$ \\
\hline
\end{tabular}

Except where otherwise indicated, values are no. (\%). 


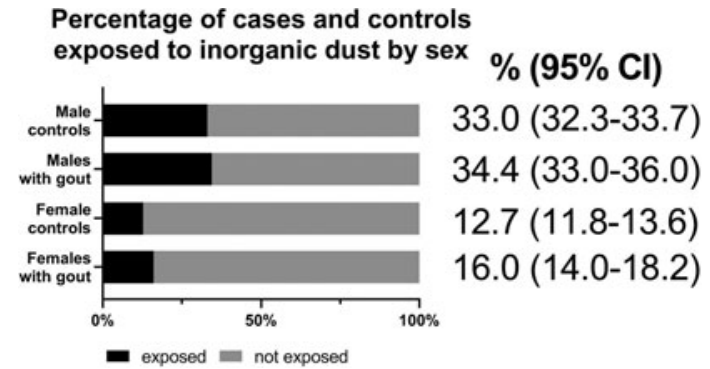

Figure 1 Percentage of male and female cases and controls exposed to inorganic dust during the 5 years before gout diagnosis or corresponding time period for controls.

level was also adjusted for, the association between inorganic dust and gout was diminished (figure 2B).

In the stratified analysis where men and women were analysed separately, exposure to inorganic dust significantly increased the odds of gout for women by $32 \%$ in the unadjusted analysis (OR 1.32, 95\% CI 1.10 to 1.58 ) and $26 \%$ in the adjusted analysis (OR 1.26, $95 \%$ CI 1.05 to 1.51 ). For men, the increase in odds of incident gout from exposure to inorganic dust was non-significant, OR $1.05,95 \%$ CI 0.97 to 1.13 in the adjusted analysis (figure 3 ).

\section{Most common occupations}

In total, 7341 individuals (6526 men and 815 womene) were defined by the JEM as exposed to inorganic dust. The five most common occupations among the exposed are shown in table 2.

The most common occupations defined as exposed differed for men and women; table 3 shows the most common dust-exposed occupations for men and women separately.

A.

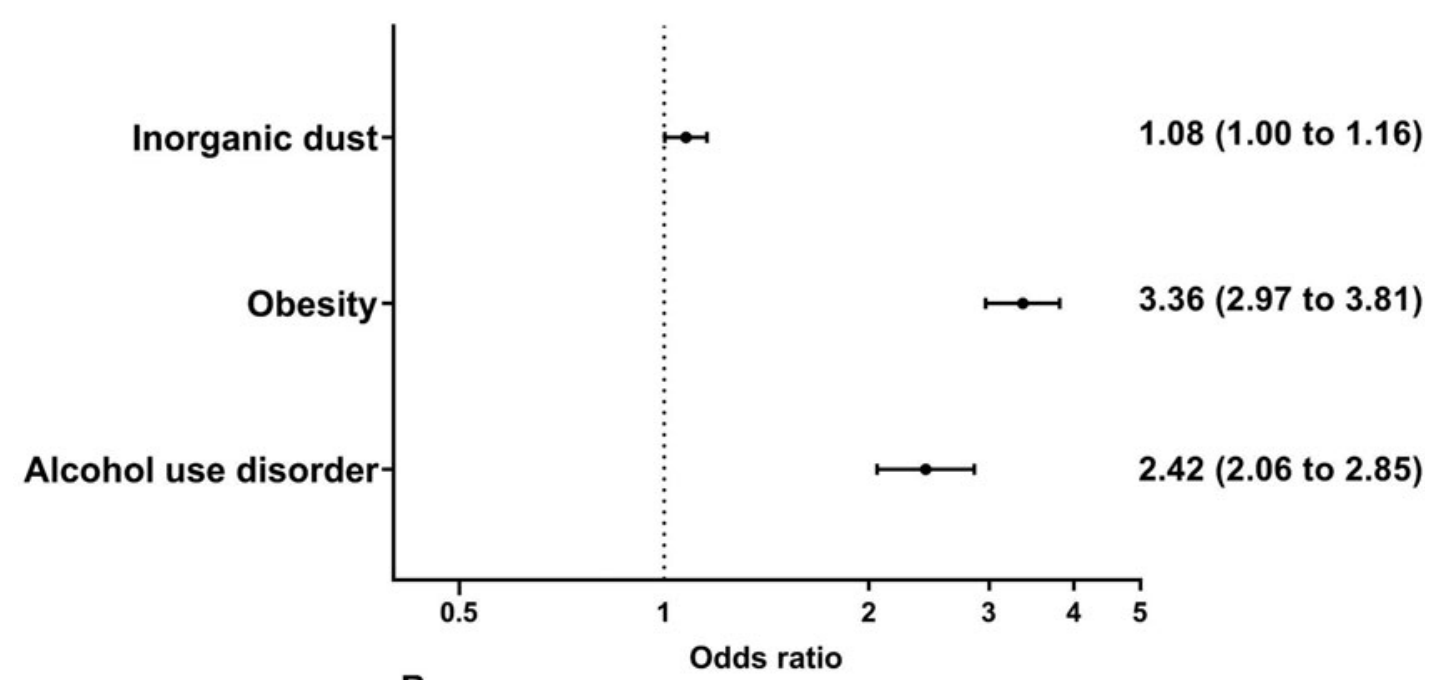

B.

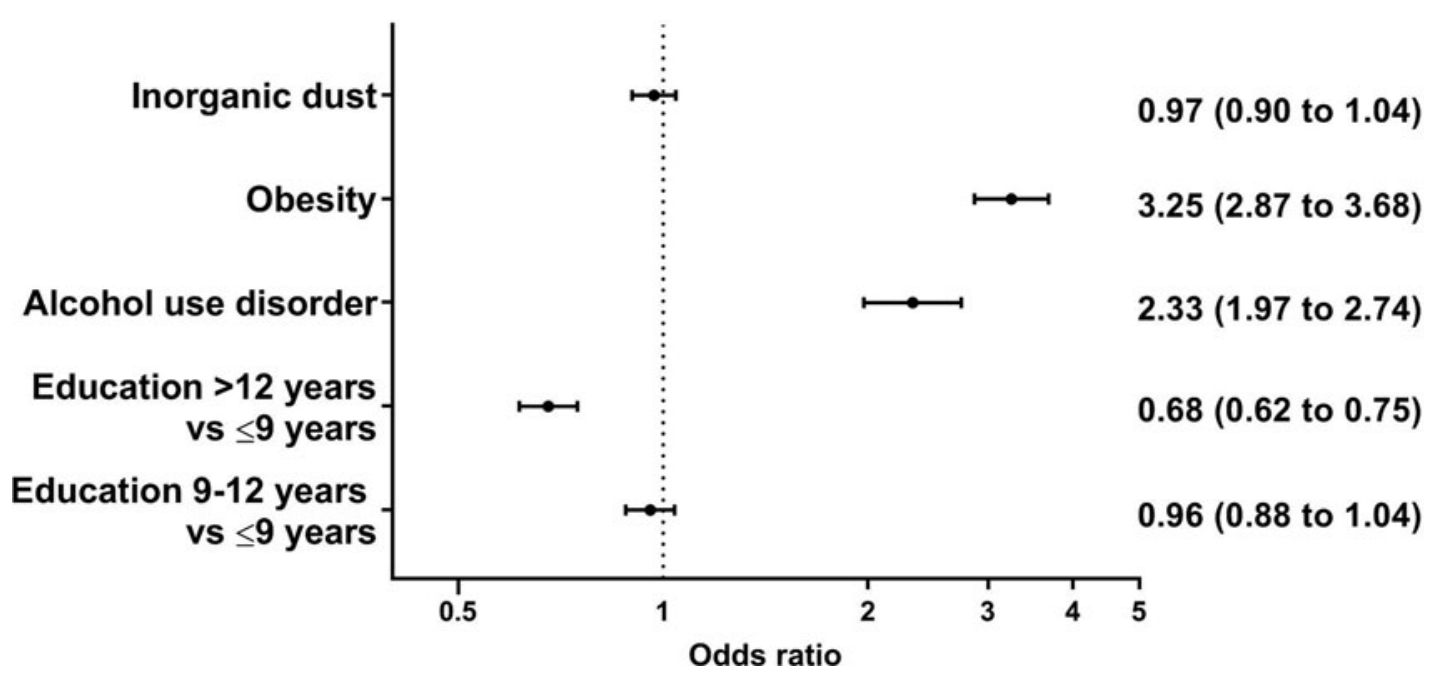

Figure 2 Predictors of incident gout. Multiadjusted odds ratios with 95\% confidence intervals. A) Main model, adjusted for obesity and alcohol use disorder. B) Secondary model, adjusted for educational level in addition to obesity and alcohol use disorder. 


\section{Women}
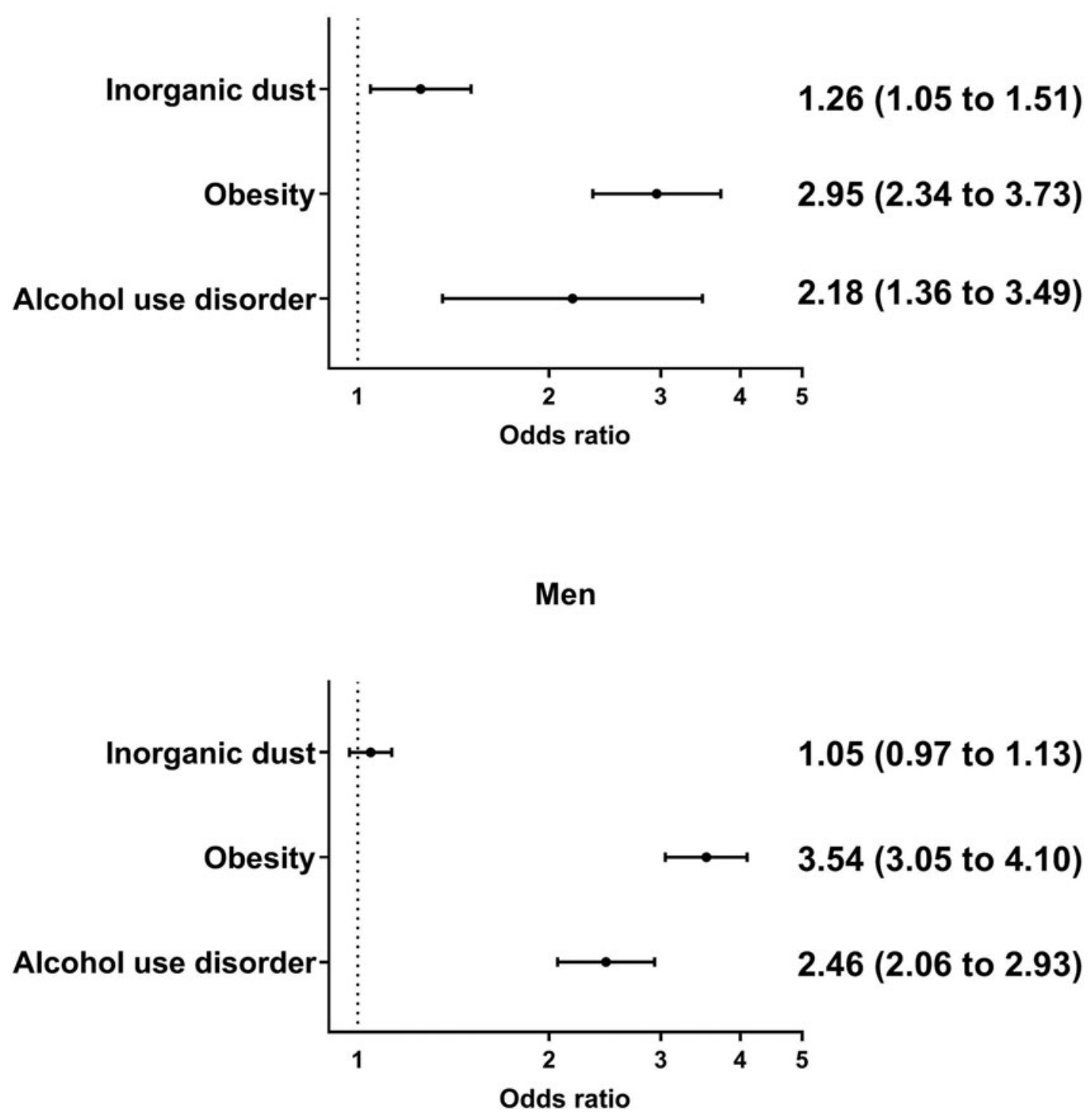

Figure 3 Predictors of incident gout in women and men. Multiadjusted odds ratios with $95 \%$ confidence intervals.

\section{DISCUSSION}

In the present study, we found that occupational exposure to inorganic dust was associated with incident gout. The association was statistically significant in women also after adjusting for confounding by diagnosed alcohol use

\begin{tabular}{ll}
\hline $\begin{array}{l}\text { Table } 2 \\
\text { dust }\end{array}$ & Most common occupations exposed to inorganic \\
\hline Occupational title & N (\%)* \\
\hline Building finishers and related trades workers & $1081(15)$ \\
Motor vehicle drivers & $672(9)$ \\
Material recording and transport clerks & $633(9)$ \\
Assemblers & $549(7)$ \\
Building frame and related trades workers & $486(7)$ \\
\hline
\end{tabular}

${ }^{*}$ Percentages refer to \% of all exposed individuals. disorder and obesity. The effect was of modest size and smaller than what has been shown in studies of dust exposure and risk of rheumatoid arthritis and systemic sclerosis. ${ }^{15} 1618$

The pathogenetic mechanism through which inorganic dust exposure might increase the risk of gout is not clear. We speculate that a possible explanation could be the phenomenon of innate immune system training, ${ }^{27}$ where priming of the innate immune system by prior inflammatory stimuli can cause increased reactivity later on. Occupational exposure to inorganic dust could possibly trigger innate immune system training through activation of the NLRP3 inflammasome, ${ }^{12}$ leading to increased interleukin-1 production and in the long run to increased responses of the innate immune system towards urate crystals, manifesting as increased incidence of clinical gout in dust-exposed individuals. 


\begin{tabular}{|c|c|c|c|}
\hline \multicolumn{2}{|c|}{$\begin{array}{l}\text { Women }-5 \text { most common } \\
\text { occupations defined as } \\
\text { exposed }\end{array}$} & \multicolumn{2}{|c|}{$\begin{array}{l}\text { Men }-5 \text { most common } \\
\text { occupations defined as } \\
\text { exposed }\end{array}$} \\
\hline Job title & n (\%)* & Job title & n (\%)t \\
\hline $\begin{array}{l}\text { Domestic and } \\
\text { related helpers, } \\
\text { cleaners and } \\
\text { launderers }\end{array}$ & $455(56)$ & $\begin{array}{l}\text { Building finishers } \\
\text { and related } \\
\text { trades workers }\end{array}$ & $\begin{array}{l}1060 \\
(16)\end{array}$ \\
\hline $\begin{array}{l}\text { Building caretakers, } \\
\text { window and related } \\
\text { cleaners }\end{array}$ & $58(7)$ & $\begin{array}{l}\text { Motor vehicle } \\
\text { drivers }\end{array}$ & $\begin{array}{l}669 \\
(10)\end{array}$ \\
\hline Assemblers & $54(7)$ & $\begin{array}{l}\text { Material } \\
\text { recording and } \\
\text { transport clerks }\end{array}$ & 587 (9) \\
\hline $\begin{array}{l}\text { Material recording } \\
\text { and transport clerks }\end{array}$ & $46(6)$ & Assemblers & 495 (8) \\
\hline $\begin{array}{l}\text { Other machine } \\
\text { operators not } \\
\text { elsewhere classified }\end{array}$ & $43(5)$ & $\begin{array}{l}\text { Building frame } \\
\text { and related } \\
\text { trades workers }\end{array}$ & $483(7)$ \\
\hline
\end{tabular}

*Percentages refer to percent of all exposed women. †Percentages refer to percent of all exposed men.

Studies on associations between air pollution and gout occurrence are scarce, but our findings of an association between dust exposure and gout are in line with a previous report from Korea, where increased levels of air pollution with fine particulate matter were associated with acute gout flares. ${ }^{19}$

Hyperuricemia and factors, like obesity and alcohol use disorder, which contribute to hyperuricemia and clinical gout are by far the most important risk factors for gout. In relation to such factors, the effects of occupational exposures are small but, as we have shown, possibly important. Uncovering novel risk factors for gout unrelated to urate metabolism could contribute to an increased understanding of the pathogenesis and help explain why only a minority of individuals with hyperuricemia develop clinical gout and in the long run possibly contribute to prevention of gout in susceptible individuals.

Other occupational exposures could also play a role in the development of clinical gout and should be investigated in further studies. There is considerable evidence that lead exposure, even when not leading to overtly elevated blood levels of lead, influences urate levels. ${ }^{28} 32$ Consequently, it should be investigated in future studies whether occupations that entail exposure to lead increase the risk of clinical gout.

There are some limitations of the study that should be discussed and acknowledged. First, there could be misclassification of exposure based on occupational coding. The validity of the occupational codes reported to the occupational register by employers has not been investigated specifically for dust-exposed occupations. In our data, occupational codes on the individual level were very consistent over the time period of 5 years, strongly suggesting that the quality of reporting of occupational codes is good. Furthermore, any occupational misclassification is likely to be non-directional, as misclassification should be equally common for cases and controls.

Second, as in all observational register studies, residual confounding could be present.

Third, misclassification of comorbidities could be a problem as they were defined by the presence of ICD10 codes. In general, the validity of ICD-10 codes in the Swedish National Patient Register is good. ${ }^{33}$ However, all diagnoses have not been validated, and under-reporting of, for example, alcohol use disorder and obesity is likely to be present, which could influence our results. Such under-reporting is however likely to be of equal magnitude for both cases and controls.

Finally, adjustment for additional possible confounders should be discussed. Whether to adjust for educational level is a complicated issue when assessing potential effects of occupational exposures. On the one hand, educational level is a marker of SES, which has an influence on the health of individuals. On the other hand, educational level is strongly connected to choice of occupation. Choice of occupation can thus be seen to be in the temporal pathway between education and clinically evident gout. Low educational level strongly predicts having a dust-exposed job. It seems unlikely that educational level in itself should cause disease. Rather, downstream effects of a short education, such as ending up in a dust-exposed job, could have biological effects and increase the likelihood of disease. Thus, adjustment for educational status could be considered to be overadjustment, that is, adjusting for an upstream mediator of the variable of interest. In line with this, in the model where educational level was adjusted for, the effect of inorganic dust exposure on risk of gout was no longer evident. This finding could either be an effect of overadjustment, or possibly it shows that socioeconomic factors, of which educational level is a marker, are of greater importance than occupational exposure to inorganic dust for the risk of gout.

Furthermore, smoking exposure could not be included in the present analyses, but although it is a risk factor for many diseases, it has not consistently been shown to associate with urate levels or clinical gout. ${ }^{34}$ Nonetheless, residual confounding due to smoking cannot be excluded.

There are also several strengths of the study. First, the population-based design, including all individuals with an incident gout diagnosis in the region, minimises the risk of selection bias. The validity of the case definition for gout used in the study has been studied and was found to be high. ${ }^{23}$ Second, the use of coded occupational titles from an official register and a JEM to determine exposure is another strength of the study, as this avoids the potential recall bias associated with retrospective self-reported occupation.

In conclusion, we describe for the first time an association between occupational exposure to inorganic dust and incident gout. 
Twitter Sigurdardottir @ValgerdurRos.

Contributors VS contributed to analysis and interpretation of data and was responsible for writing the manuscript. MD, LJ and KT contributed to the conception of the study, the acquisition, analysis and interpretation of data and contributed to writing the manuscript. AS contributed to the interpretation of data and the writing of the manuscript. LS was responsible for the statistical analysis and contributed to the writing the manuscript.

Funding The authors have not declared a specific grant for this research from any funding agency in the public, commercial or not-for-profit sectors.

Competing interests None declared.

Patient consent for publication Not required.

Ethical approval information Ethical approval for the study was granted from the Ethical Review Board of Gothenburg, Sweden (347/13). Patient consent was waived, as data were derived from administrative registers that do not require such consent.

Provenance and peer review Not commissioned; externally peer reviewed.

Data sharing statement Statistical analysis plan available upon request. Individual participant data not available due to legal restrictions prohibiting sharing of register data.

Open access This is an open access article distributed in accordance with the Creative Commons Attribution Non Commercial (CC BY-NC 4.0) license, which permits others to distribute, remix, adapt, build upon this work non-commercially, and license their derivative works on different terms, provided the original work is properly cited, appropriate credit is given, any changes made indicated, and the use is non-commercial. See: http://creativecommons.org/licenses/by-nc/4.0/.

ORCID iD

Valgerdur Sigurdardottir http://orcid.org/0000-0002-9907-4901

\section{REFERENCES}

1 Roughley MJ, Belcher J, Mallen CD, et al. Gout and risk of chronic kidney disease and nephrolithiasis: meta-analysis of observational studies. Arthritis Res Ther 2015:17.

2 Juraschek SP, Kovell LC, Miller ER, et al. Association of kidney disease with prevalent gout in the United States in 1988-1994 and 2007-2010. Semin Arthritis Rheum 2013;42:551-61.

3 Tu H-P, Tung Y-C, Tsai W-C, et al. Alcohol-related diseases and alcohol dependence syndrome is associated with increased gout risk: a nationwide population-based cohort study. Joint Bone Spine 2017;84:189-96

4 Choi HK, Atkinson K, Karlson EW, et al. Alcohol intake and risk of incident gout in men: a prospective study. Lancet 2004;363:1277-81.

5 Bruderer S, Bodmer M, Jick SS, et al. Use of diuretics and risk of incident gout: a population-based case-control study. Arthritis Rheumatol 2014;66:185-96.

6 Rassen JA, Bartels DB, Schneeweiss S, et al. Measuring prevalence and incidence of chronic conditions in claims and electronic health record databases. Clin Epidemiol 2018;11:1-15.

7 Public Health Agency of Sweden. Öppna Jämförelser Folkhälsa 2019. 2019. Available from: https://www.folkhalsomyndigheten.se/ contentassets/ec714fca0b0145eab3d7924511550a74/oppna-jam forelser-folkhalsa-2019-18076.pdf (accessed 1302 2019)

8 Gardner MJ, Power C, Barker DJ, et al. The prevalence of gout in three English towns. Int J Epidemiol 1982;11:71-5.

9 Kapetanovic MC, Hameed M, Turkiewicz A, et al. Prevalence and incidence of gout in Southern Sweden from the socioeconomic perspective. RMD Open 2016;2:e000326.

10 Hayward RA, Rathod T, Roddy E, et al. The association of gout with socioeconomic status in primary care: a cross-sectional observational study. Rheumatology (Oxford) 2013;52:2004-8.

11 Vazquez-Mellado J, Cruz J, Guzman S, et al. Severe tophaceous gout. Characterization of low socioeconomic level patients from México. Clin Exp Rheumatol 2006;24:233-8.
12 Peeters PM, Perkins TN, Wouters EF, et al. Silica induces NLRP3 inflammasome activation in human lung epithelial cells. Part Fibre Toxicol 2013;10:3.

13 Martinon F, Petrilli V, Mayor A, et al. Gout-associated uric acid crystals activate the NALP3 inflammasome. Nature 2006;440:237-41.

14 Maciejewska A. Health effects of occupational exposure to crystalline silica in the light of current research results. Med $\mathrm{Pr}$ 2014;65:799-818.

15 Vihlborg P, Bryngelsson IL, Andersson L, et al. Risk of sarcoidosis and seropositive rheumatoid arthritis from occupational silica exposure in Swedish iron foundries: a retrospective cohort study. BMJ Open 2017;7:e016839.

$16 \operatorname{llar}$ A, Alfredsson L, Wiebert $\mathrm{P}$, et al. Occupation and risk of developing rheumatoid arthritis: results from a population-based case-contro study. Arthritis Care Res (Hoboken) 2018;70:499-509.

17 Too CL, Muhamad NA, Ilar A, et al. Occupational exposure to textile dust increases the risk of rheumatoid arthritis: results from a Malaysian population-based case: control study. Ann Rheum Dis 2016;75:9971002.

18 Blanc PD, Jarvholm B, Toren K. Prospective risk of rheumatologic disease associated with occupational exposure in a cohort of male construction workers. Am J Med 2015;128:1094-101.

19 Ryu H, Seo M, Choi H, et al. THU0427 Ambient air pollution and risk of acute gout flares: a time-series study. Ann Rheum Dis 2017;76:369-

20 Statistics Sweden. Folkmängden efter region, civilstånd, ålder och kön. År 1968-2014. 2012. Available from: https://www.statistikdatabasen.scb.se/ pxweb/sv/ssd/START_BE_BE0101A/BefolkningNy/?rxid=35ac0e2cOf41-4674-8730-34d07c219c88. (accessed 202006 29).

21 Ministry of Health and Social Affairs SGO. Updated high-cost protection: outpatient care and medication.

22 International Labour Office. International Standard Classification of Occupations: ISCO-88. Geneva: International Labour Office, 1991.

23 Dehlin M, Stasinopoulou K, Jacobsson L. Validity of gout diagnosis in Swedish primary and secondary care - a validation study. BMC Musculoskelet Disord 2015;16:149.

24 Lillienberg L, Andersson E, Janson C, et al. Occupational exposure and new-onset asthma in a population-based study in Northern Europe (RHINE). Ann Occup Hyg 2013;57:482-92.

25 Toren K, Blanc PD, Naidoo RN, et al. Occupational exposure to dust and to fumes, work as a welder and invasive pneumococcal disease risk. Occup Environ Med 2020;77:57-63.

26 Choi HK, Atkinson K, Karlson EW, et al. Obesity, weight change, hypertension, diuretic use, and risk of gout in men: the health professionals follow-up study. Arch Intern Med 2005;165:742-8.

27 Moorlag S, Roring RJ, Joosten LAB, et al. The role of the interleukin-1 family in trained immunity. Immunol Rev 2018;281:28-39.

28 Baki AE. The effects of lead exposure on serum uric acid and hyperuricemia in young adult workers: a cross-sectional controlled study. Archives Rheumatol 2016;31:71-5.

29 Dai $\mathrm{H}$, Huang Z, Deng Q, et al. The effects of lead exposure on serum uric acid and hyperuricemia in Chinese adults: a cross-sectional study. Int J Environ Res Public Health 2015;12:9672-82.

30 Lee D, Choi W-J, Oh J-S, et al. The relevance of hyperuricemia and metabolic syndrome and the effect of blood lead level on uric acid concentration in steelmaking workers. Annals Occup Env Med 2013;25:27.

31 Krishnan E, Lingala B, Bhalla V. Low-level lead exposure and the prevalence of gout: an observational study. Ann Intern Med 2012;157:233-41.

32 Alasia DD, Emem-Chioma PC, Wokoma FS. Association of lead exposure, serum uric acid and parameters of renal function in Nigerian lead-exposed workers. Int J Occup Environ Med 2010;1:182-90.

33 Ludvigsson JF, Andersson E, Ekbom A, et al. External review and validation of the Swedish national inpatient register. BMC Public Health 2011;11:450.

34 Fanning N, Merriman TR, Dalbeth N, et al. An association of smoking with serum urate and gout: a health paradox. Semin Arthritis Rheum 2018;47:825-42.

35 Statistics Sweden. Background Facts. Labour and education statistics. 2011. Available from: https://www.scb.se/contentassets/f1ebeae6 d63544edb9a83148b5674271/am0208_2011a01_br_am76br1105.pdf (accessed: 202006 30). 